\title{
Potential clinically useful prognostic biomarkers in triple-negative breast cancer: preliminary results of a retrospective analysis
}

This article was published in the following Dove Press journal: Breast Cancer - Targets and Therapy

\author{
Silvia Mihaela Ilie' \\ Xenia Elena Bacinschi ${ }^{1,2}$ \\ Inga Botnariuc ${ }^{2}$ \\ Rodica Maricela Anghel ${ }^{1,2}$ \\ 'University of Medicine and \\ Pharmacy "Carol Davila," Bucharest, \\ Romania; ${ }^{2}$ Department of Oncology- \\ Radiotherapy, Institute of Oncology \\ "Prof Dr Alexandru Trestioreanu," \\ Bucharest, Romania
}

Background: Triple-negative breast cancer (TNBC) has a poor prognosis, even in its early stages. In the absence of postoperative targeted treatments, intensive adjuvant chemotherapy regimens are proposed. For those favorable histologies, such as apocrine and adenoid cystic carcinoma, which frequently belong to TNBC, aggressive treatments are unnecessary.

Patients and methods: We retrospectively analyzed 631 cases of breast cancer, primary operated curatively, and followed up at our institution for at least 36 months to identify the biomarkers assessable by immunohistochemistry, to be proposed as prognostic score for tailoring adjuvant treatment to TNBC patients.

Results: The triple-negative phenotype was found in 85 patients (13.5\%). Over a mean followup of 55.7 months, relapses occurred in 106 patients $(16.8 \%)$, of which $18(2.8 \%)$ were TNBC. Recurrence was directly correlated with $\mathrm{Ki} 67$ and cytokeratin 5/6 (CK5/6) immunoreactivity in all breast cancer patients $(P=0.005)$, but only marginally with $\mathrm{CK} 5 / 6$ and epithelial cadherin (E-cad) expression in TNBC patients $(P=0.07)$. Mean event-free survival (EFS) in TNBC patients was 85.52 months compared with 100.4 months in non-TNBC patients $(P=0.228)$. The EFS of CK5/6-negative triple-negative patients was 68.84 months compared with 98.84 months in those who were $\mathrm{CK} 5 / 6$ positive $(\mathrm{HR}=5.08 ; P=0.038)$. EFS differed among patients identified as double-positive for E-cad and CK5/6 (83.87 months), those expressing E-cad or CK5/6 (64.23 months), and those negative for both biomarkers (39.64 months).

Conclusion: These preliminary results suggest that CK5/6 and E-cad are possible core biomarkers for a cost-effective prognostic evaluation of primary operable TNBC patients.

Keywords: prognosis, immunohistochemical biomarkers, triple-negative breast cancer, CK5/6, E-cadherin

\section{Introduction}

Breast cancer, the leading cause of cancer-related death in women, comprises a heterogeneous group of diseases that vary regarding morphology, biology, and prognosis. The different subtypes of breast cancer are based on the expression of certain receptors on the surfaces of tumor cells. ${ }^{1,2}$

One of the first classification systems reported in 2001 was based on microarray mRNA quantitative measurement. Five molecularly distinct intrinsic subtypes were identified according to genes' clusters from two main types of cells in human mammary glands (luminal and basal or myoepithelial) and human epidermal growth factor receptor 2 (HER2) and hormone receptor genes expression. However, microarray-based gene expression profiling technologies remain impractical for the routine analysis of tumor specimens due to the high cost and complexity associated with sample preparation, assays, and data analysis. ${ }^{3-5}$
Silvia Mihaela Il Trestioreanu," Fundeni Street, No 252 Bucharest, Romania

Tel +40 728577326

Email silviailie@gmail.com 
Closely following the early invasive breast cancer classification system of Voduc et al, which is based on the immunohistochemical (IHC) semiquantitative analysis of the estrogen receptor (ER), progesterone receptor (PR), Ki67 (nuclear antigen, marker of proliferation), and HER2 expressions, a four-surrogate breast cancer classification system similar to that of the intrinsic subtypes was adopted and recommended by international guidelines. ${ }^{6,7}$ Triple-negative breast cancer (TNBC) represents the phenotype that expresses very low levels of ER, PR, and HER2 and accounts for $10 \%-20 \%$ of all invasive breast cancers, representing over 170,000 of the one million cases diagnosed annually. ${ }^{8}$ TNBC is the IHC surrogate for the microarray-based profiling of basal-like breast cancer. According to recommendations by the American Society of Clinical Oncology (ASCO) and the College of American Pathologists (CAP), TNBC is defined by $<1 \%$ of invasive cells staining for ER and PR expression, by either a $0-1+$ or $2+$ expression score as determined by IHC, and by testing negative in situ hybridization (ISH) for $E R B B 2$ (gene encoding HER2 not amplified). ${ }^{9,10}$

TNBC is associated with young age, high proliferative index, poor prognosis, premature relapse (2-3 years), high rate of visceral metastasis (primarily lung, liver, and brain), and short median time to death (9 months). ${ }^{11-14}$ Even in very early stages, such as T1N0-1, the 5-year relapse-free survival (RFS) rate is poor $(85 \%-89 \%) .{ }^{15}$ The presumption of an aggressive clinical course and the absence of targeted adjuvant treatments for TNBC have resulted in the overuse of intensified postoperative chemotherapy; for example, the European and North American guidelines recommend starting adjuvant chemotherapy at a $0.6-\mathrm{cm}$ pathological diameter and preferably using dose-dense regimens. ${ }^{16-19}$ Nevertheless, in one retrospective study, two-thirds of early-stage TNBC patients $(\mathrm{N}=117)$ treated conservatively by surgery remained disease-free after 5 years without any adjuvant chemotherapy. ${ }^{20}$ A proportion of favorable histologies, such as medullary or adenoid cystic carcinoma, frequently belongs to the triple-negative phenotype, for which chemotherapy is not necessary. ${ }^{21}$ To identify aggressive or nonaggressive subtypes, the gene-profiling microarray technique would be desirable; yet, pecuniary and feasibility reasons mean that an assessment by IHC methods is more convenient for everyday practice.

Gene expression analysis has revealed that TNBC comprises several subtypes displaying different targets and outcomes, such as a mesenchymal-like cell subtype with phosphatidylinositol-4,5-bisphosphate 3-kinase (PI3K) catalytic subunit alpha mutations in almost $50 \%$ of cases, phosphatase and tensin homolog deficiencies, or a luminal androgen receptor (LAR) subtype with overactivated PI3K/ mammalian target of rapamycin pathway signaling. RFS was significantly lower in the LAR subtype than in the basal-like $(\mathrm{HR}=2.9)$, and when compared with the mesenchymal stemlike subtype $(\mathrm{HR}=10.5 ; P<0.05) .{ }^{22}$ However, unlike other breast cancer subtypes, the classical prognostic signatures based on gene modules known to regulate or execute cell proliferation did not show any value in highly proliferative hormone-negative breast cancers. ${ }^{23}$

Staining by IHC techniques is the surrogate for the assessment of many aberrant proteins that result from gene mutations or deletions, although the specificity compared with that of a gene assay is $\sim 80 \% .{ }^{24}$ Most analyses that attempt to characterize this phenotype use formalin-fixed paraffinembedded tissue specimens. ${ }^{25}$

Lately, a plethora of biomarkers has been associated with the basal-like or triple-negative phenotype. However, only some of them have been validated in independent series, whereas very few have been compared with gene expression and no study has compared a large number of these candidate biomarkers in parallel. ${ }^{26}$ The prognostic roles of several biomarkers in TNBC have been studied, including assessments of correlated biomarker clusters, with a view to create a prognostic score. ${ }^{27}$

Considering everyday clinical practice needs, we analyzed several biomarkers assessable by IHC according to literature findings and institutional laboratory assessments to provide a prognostic stratification for patients diagnosed with upfront operable localized TNBC that could be used as a means of adapting adjuvant treatment.

\section{Materials and methods Study design}

We performed a retrospective analysis in localized breast cancer female patients addressed for curative primary surgical treatment at the Institute of Oncology, Bucharest from January 2005 to December 2012. Only data from patients with invasive histology, for whom a surgical specimen was evaluated by IHC and who were followed up for at least 36 months, were retained for the study. All patients provided written consent for invasive procedures as well as for the prospective collection of their data. The study was conducted in accordance with the Declaration of Helsinki and approved by the review board of Institute of Oncology "Prof Dr Alexandru Trestioreanu," Bucharest, Romania. Patients with a history of metachronous breast cancer, at a metastatic stage of the disease, with an in situ-only histology, or for whom surgery 
was of a palliative intent or sequential after neoadjuvant treatment were excluded from our analysis.

\section{Patients}

The general population was classified into five intrinsic subgroups on the basis of pathological parameters and according to the 2015 St Gallen Consensus Conference, as follows: luminal A, ER and PR positive, HER2 negative, tumor grade 1-2, $\mathrm{Ki} 67 \leq 20 \%$; luminal $\mathrm{B}, \mathrm{ER}$ and/or PR positive, HER2 negative, tumor grade 3, Ki67 >20\%; luminal B HER2 overexpressing, ER, PR, and HER2 positive; HER2 overexpressing, ER and PR negative, HER2 positive; and triple-negative, ER, PR, and HER2 negative. ${ }^{7}$

The threshold for the definition of TNBC was $<1 \%$ immunopositivity of either ER or PR and an immunoscore of 0 or 1+ for HER2 expression or 2+ in the absence of amplification by fluorescent ISH. A comparative subgroup analysis was conducted between the TNBC population and all other patients in the overall population displaying hormonal and/or HER2 overexpressing features, conventionally named non-TNBC.

We considered 2005 to be the starting year of our analysis, because it was then that the TNBC phenotype was recognized as a distinct breast cancer subgroup. Regarding therapeutic considerations, systemic adjuvant treatment was proposed for all patients according to European guidelines available at the time, and the clinical stage was updated according to the American Joint Committee on Cancer, seventh edition. ${ }^{28}$ External radiotherapy was provided according to institutional guidelines. Anti-HER2 monoclonal antibody therapy with trastuzumab only became available for systemic therapy in 2007, when it was approved for general use in Romania.

We analyzed several independent variables such as demographics (age, menopausal status, family history of cancer, Charlson comorbidity index, and body mass index [BMI]), clinical tumor characteristics (laterality, involved quadrant, tumor size, clinical stage, and type of surgery), histopathological features (histopathological type, pathologic stage of regional lymphnode (pTN) stage, size of invasive component in millimeters, multifocality/multicentricity status, lymph node status, lymphovascular invasion, and in situ component), IHC characteristics (expression of ER and PR, HER2, and Ki67), and treatment-related features (chemotherapy regimen and radiotherapy provided).

\section{Histopathological and IHC analysis and scoring}

Histopathological and IHC tumor specimen assessments were carried out on formalin-fixed paraffin-embedded tissue sections selected to include representative sections of carcinomas and adjacent normal breast tissue. Tumor grading was performed, as described by Elston and Ellis, in relation to tubule formation, nuclear grade, mitotic status, and peritumoural vascular invasion according to the Rosen score. ${ }^{29,30}$ Standard IHC analysis was performed using standard procedures on $4-\mu \mathrm{m}$ sections of paraffin-embedded tissue specimens stained with the corresponding antibodies. The tumor cell staining was compared with that of the surrounding normal breast epithelium, used as the negative control. The slides were scored according to the percentage of positive cells vs total cell number, regardless of staining intensity for non-standardized biomarkers. The immunostaining scores for ER, PR, and Ki67 and the algorithm for HER2 scoring were determined according to ASCO and CAP guidelines. ${ }^{10,11}$ The antibodies used for ER, PR, and HER2 staining, as well as those used for the other biomarkers assessed, are listed in Supplementary materials.

Cell proliferation (Ki67) was assessed by nuclear staining in at least 500 tumor cells using a mouse monoclonal antibody, clone MIB1 (Dako Denmark A/S, Glostrup, Denmark) at a 1/100 dilution. By convention, we considered the expression level of $\mathrm{Ki} 67$ to be low if the percentage of nuclear staining was $<20 \%$, intermediate if between $21 \%$ and $60 \%$, and high if $\geq 60 \%$.

For each of the biomarkers (cytokeratin 5/6 [CK5/6], EGFR, epithelial cadherin [E-cad], tumor protein p53, B-cell lymphoma 2 [Bcl2], topoisomerase II alpha [TOP2A], and cyclooxygenase-2 [Cox-2]), the assessment was considered to be "positive" if at least $10 \%$ of the tumor cell specimens were stained according to the internal criteria of the laboratory. The number of invasive tumor cells showing definitive immunoreactivity for the corresponding antigen was $>2,000$ neoplastic cells at least. The studied biomarkers were assessed regarding correlations with other clinical, pathological, and treatment-related variables as well as with a relapse/no relapse status. These correlations were further assessed to be used as a prognostic score in the specific population.

\section{Study outcome}

The primary outcome of interest was the association of biomarker expression with the estimated event-free survival (EFS) in the specific population, where EFS is the time elapsed between the date of surgery and the date of first recurrence, diagnosis of a second malignancy, or death resulting from any cause. Further, biomarkers that might predict relapse and EFS in the subpopulations were stratified according to biomolecular clustering and differences in 
expression according to the relapsed or non-relapsed status evaluated at the study's end, in both the general and the specific populations.

\section{Statistical analyses}

Statistical analyses were conducted using SPSS version 22 (IBM Corporation, Armonk, NY, USA). The chi-squared test determined the correlation between biomarkers and other clinical and histological variables, and logistic regression predicted relapse based on these correlations. Fisher's exact test was employed when there were fewer than five cases in any cell of the $2 \times 2$ table. The association between variables and survival was analyzed using Cox proportional hazard regression analysis. Survival curves were generated using the Kaplan-Meier method and compared using the log-rank test. HRs and 95\% CIs for the variables were calculated using the Cox proportional hazard model. ${ }^{31}$

All statistical tests were two-sided, and a $P$-value $<0.05$ was considered to be significant. All analyses were based on the observed data with the assumption that missing data were randomly distributed.

\section{Results}

\section{Patient and disease characteristics}

After excluding files with essential missing data, 631 cases referred for surgery in our institution were chosen for the final analysis. In the general breast cancer patient population (Table 1), the average age was 53.7 years, ranging between 24 and 81 years. Further, 79.4\% (501) were postmenopausal, and a family history of cancer was recorded in $15.7 \%$ (99). The main concern was the external quadrant in $58.9 \%$ of cases (372) and those more likely to have stage II of the disease $(500 ; 79.24 \%)$. Radical surgery was the initial treatment in 448 patients $(71 \%)$, and all were exposed to adjuvant chemotherapy and irradiation. Most participants $(518 ; 82.1 \%)$ had invasive ductal carcinoma histology, 85 (13.5\%) displayed characteristics of the TNBC phenotype, 228 (36.13\%) bore a luminal A subtype, 261 (41.36\%) bore a luminal B subtype, and $57(9.03 \%)$ had HER2 overexpressing tumors, of which $26(4.12 \%)$ were hormonal receptor negative (Table 1$)$.

Regarding the histopathological and IHC characteristics, the primary tumor (pT) stage was primarily pT1b-pT2 in 569 patients $(90.2 \%)$, the tumor grade was II for 346 patients (54.83\%), lymph node involvement was recorded in 264 patients (41.64\%), and lymphovascular invasion was seen in 550 patients $(87.16 \%)$. The average expression of ER was $38.6 \%$ (range, $0 \%-80 \%$ ), and for PR it was $31.3 \%$ (range, $0 \%-95 \%$ ), with more than half of the cases displaying a score $>10 \%(67.8 \%, 429$ patients and $60.7 \%, 383$ patients, respectively). The mean score of $\mathrm{Ki} 67$ was $25.2 \%$ (range, $1 \%-80 \%$ ) in $5.7 \%$ being superior to $60 \%$. The expression of HER2, as determined by IHC, was positive or equivocal in 118 patients $(18.7 \%)$.

The average age in the TNBC population was 52.3 years, of which $28.2 \%$ (24 patients) were premenopausal, $7 \%$ (six patients) had a recorded family history of cancer, and $88.2 \%$ (75 patients) were stage II, whereas the external and internal mammary quadrants were proportionally involved. Radical mastectomy was the surgical approach in $60 \%$ of cases (51 patients) (Table 1). The histopathology in cases other than invasive ductal carcinoma was medullary carcinoma $(4.7 \%$, four patients) and metaplastic carcinoma (1.2\%, one patient). Tumor grade III was predominant (63 patients, $74.1 \%$ ), tumor stage pT2 was noted in 51 patients $(60 \%)$, nodal involvement was recorded in $34.1 \%$ (29 patients), and lymphovascular invasion was identified in four cases (4.7\%). HER2 was expressed in 10 cases (11.8\%), while Ki67 expression ranged between $5 \%$ and $80 \%$, with an average of $44.7 \%$. More than half $(58.8 \%)$ of the patients had a Ki67 value between $21 \%$ and $60 \%$, and $23.5 \%$ had a value $>60 \%$. All patients underwent adjuvant chemotherapy, which contained anthracycline in 44 cases $(51.8 \%)$.

\section{Biomarker expression and correlations}

In the general population, EGFR expression was significantly directly correlated with tumor grade $(P=0.002)$, lymph node involvement $(P=0.006)$, capsular effraction $(P=0.011)$, and hormone receptor expression $(P=0.004)$, and E-cad was significantly directly correlated with tumor stage $(P=0.03)$, and Ki67 $(P=0.003)$ and PR $(P=0.007)$ expression. CK5/6 positivity was significantly correlated with the clinical stage $(P=0.0039)$ and the presence of an in situ component $(P=0.027)$. The positivity of $\mathrm{p} 53$ was significantly correlated with quadrant involvement (internal vs external; $P=0.028)$, pT $(P=0.028)$, the multifocal character of the tumor $(P=0.028)$, and the IHC surrogate phenotype $(P<0.0001)$. Positive $\mathrm{Bcl} 2$ staining was directly correlated with the $\mathrm{Ki} 67$ score $(P=0.006)$ and phenotype $(P=0.002)$, whereas Cox-2 was directly correlated with the clinical stage $(P<0.0001)$ and pT $(P=0.0025)$. Significant direct correlations with the phenotype were also found for the remaining three biomarkers (p53, $P<0.0001 ; \mathrm{Bcl} 2, P=0.002$; $\mathrm{Cox}-2, P=0.004)$, whereas TOP2A was significantly directly correlated with HER2 expression $(P=0.003)$.

The frequency of biomarker expression in relapsed vs non-relapsed breast cancer patients significantly correlated 
Table I Baseline characteristics in the general population and in non-TNBC vs TNBC population

\begin{tabular}{|c|c|c|c|c|c|c|c|}
\hline \multirow[t]{2}{*}{ Variables/population } & \multicolumn{2}{|c|}{$\begin{array}{l}\text { BC population } \\
631(100 \%)\end{array}$} & \multicolumn{2}{|c|}{$\begin{array}{l}\text { Non-TNBC } \\
546(86.5 \%)\end{array}$} & \multicolumn{2}{|c|}{$\begin{array}{l}\text { TNBC } \\
85(13.5 \%)\end{array}$} & \multirow[t]{2}{*}{$P$-value } \\
\hline & No & $\%$ & No & $\%$ & No & $\%$ & \\
\hline Age (years)/mean/range & 53.7 & [24-8I] & 53.9 & {$[28-81]$} & 52.2 & [24-80] & 0.205 \\
\hline \multicolumn{8}{|l|}{ Menopausal status } \\
\hline Premenopausal & 130 & 20.60 & 106 & 19.41 & 24 & 28.24 & \multirow[t]{2}{*}{0.061} \\
\hline Postmenopausal & 501 & 79.40 & 440 & 80.59 & 61 & 71.76 & \\
\hline \multicolumn{8}{|l|}{ Quadrant } \\
\hline External & 372 & 58.95 & 326 & 59.71 & 46 & 54.12 & \multirow[t]{3}{*}{0.001} \\
\hline Internal & 172 & 27.26 & 136 & 24.91 & 36 & 42.35 & \\
\hline Central & 87 & 13.79 & 84 & 15.38 & 3 & 3.53 & \\
\hline \multicolumn{8}{|l|}{ Clinical stage } \\
\hline $\mathrm{I}$ & 121 & 19.18 & 111 & 20.33 & 10 & 11.76 & \multirow[t]{3}{*}{0.068} \\
\hline II A, II B & 500 & 79.24 & 425 & 77.84 & 75 & 88.24 & \\
\hline III A, III B & 10 & 1.58 & 10 & 1.83 & 0 & 0.00 & \\
\hline \multicolumn{8}{|l|}{ Type of surgery } \\
\hline Sectorectomy & 183 & 29.00 & 149 & 27.29 & 34 & 40.00 & \multirow[t]{2}{*}{0.016} \\
\hline Mastectomy & 448 & 71.00 & 397 & \begin{tabular}{|l|}
$72.7 I$ \\
\end{tabular} & 51 & 60.00 & \\
\hline \multicolumn{8}{|l|}{ Histopathology type } \\
\hline IDC & 518 & 82.09 & 438 & 80.22 & 80 & 94.12 & \multirow[t]{4}{*}{0.001} \\
\hline ILC & 38 & 6.02 & 38 & 6.96 & 0 & 0.00 & \\
\hline Mixed IDC/ILC & 60 & 9.51 & 60 & 10.99 & 0 & 0.00 & \\
\hline Other type & 15 & 2.38 & 10 & 1.83 & 5 & 5.88 & \\
\hline \multicolumn{8}{|l|}{ pT } \\
\hline $\mathrm{pTIa}$ & 21 & 3.33 & 21 & 3.85 & 0 & 0.00 & \multirow[t]{6}{*}{0.008} \\
\hline pTIb, pTIc & 292 & 46.28 & 261 & 47.80 & 31 & 36.47 & \\
\hline pT2 & 277 & 43.90 & 226 & 41.39 & 51 & 60.00 & \\
\hline pT3 & 7 & 1.11 & 7 & 1.28 & 0 & 0.00 & \\
\hline $\mathrm{pT} 4$ & 11 & 1.74 & 11 & 2.01 & 0 & 0.00 & \\
\hline Unknown & 23 & 3.65 & 20 & 3.66 & 3 & 3.53 & \\
\hline Histologic grade & & & & & & & \\
\hline GI & 46 & 7.29 & 44 & 8.06 & 2 & 2.35 & 0.001 \\
\hline G2 & 346 & 54.83 & 328 & 60.07 & 18 & 21.18 & \\
\hline G3 & 212 & 33.60 & 149 & 27.29 & 63 & 74.12 & \\
\hline Unknown & 27 & 4.28 & 25 & 4.58 & 2 & 2.35 & \\
\hline $\mathrm{pN}$ & & & & & & & \\
\hline 0 & 367 & 58.16 & 311 & 56.96 & 56 & 65.88 & 0.354 \\
\hline $\mathrm{la}$ & 185 & 29.32 & 163 & 29.85 & 22 & 25.88 & \\
\hline $2 a$ & 58 & 9.19 & 52 & 9.52 & 6 & 7.06 & \\
\hline $3 a$ & 21 & 3.33 & 20 & 3.66 & 1 & 1.18 & \\
\hline Lymphovascular invasion & & & & & & & \\
\hline No & 550 & 87.16 & 476 & 87.18 & 74 & 87.06 & 0.732 \\
\hline Yes & 35 & 5.55 & 31 & 5.68 & 4 & 4.71 & \\
\hline Unknown & 46 & 7.29 & 39 & 7.14 & 7 & 8.24 & \\
\hline In situ pattern & & & & & & & \\
\hline No & 513 & 81.30 & 439 & 80.40 & 74 & 87.06 & 0.148 \\
\hline Yes & 91 & 14.42 & 83 & 15.20 & 8 & 9.41 & \\
\hline Unknown & 27 & 4.28 & 24 & 4.40 & 3 & 3.53 & \\
\hline HER2 expression & & & & & & & \\
\hline Negative & 366 & 58.00 & 295 & 54.03 & 71 & 83.53 & 0.001 \\
\hline I+ & 147 & 23.30 & 137 & 25.09 & 10 & 11.76 & \\
\hline $2+\mathrm{ISH}$ negative & 61 & 9.67 & 57 & 10.44 & 4 & 4.71 & \\
\hline $2+\mathrm{ISH}$ positive & 22 & 3.49 & 22 & 4.03 & 0 & 0.00 & \\
\hline Positive & 35 & 5.55 & 35 & 6.41 & 0 & 0.00 & \\
\hline Ki67 & & & & & & & \\
\hline$<20 \%$ & 329 & 52.14 & 314 & $57.5 \mathrm{I}$ & 15 & 17.65 & 0.001 \\
\hline $20 \%-60 \%$ & 266 & 42.16 & 216 & 39.56 & 50 & 58.82 & \\
\hline$>60 \%$ & 36 & 5.71 & 16 & 2.93 & 20 & 23.53 & \\
\hline
\end{tabular}


Table I (Continued)

\begin{tabular}{|c|c|c|c|c|c|c|c|}
\hline \multirow[t]{2}{*}{ Variables/population } & \multicolumn{2}{|c|}{$\begin{array}{l}\text { BC population } \\
631(100 \%)\end{array}$} & \multicolumn{2}{|c|}{$\begin{array}{l}\text { Non-TNBC } \\
546(86.5 \%)\end{array}$} & \multicolumn{2}{|c|}{$\begin{array}{l}\text { TNBC } \\
85(13.5 \%)\end{array}$} & \multirow[t]{2}{*}{ P-value } \\
\hline & No & $\%$ & No & $\%$ & No & $\%$ & \\
\hline \multicolumn{8}{|l|}{ Cytotoxic regimen } \\
\hline Antr only & 344 & 54.52 & 300 & 54.95 & 44 & 51.76 & \multirow[t]{4}{*}{0.219} \\
\hline Antr and Tax & 150 & 23.77 & 127 & 23.26 & 23 & 27.06 & \\
\hline Tax only & 13 & 2.06 & 9 & 1.65 & 4 & 4.71 & \\
\hline Other regimens & 124 & 19.65 & 110 & 20.15 & 14 & 16.47 & \\
\hline \multicolumn{8}{|l|}{ Relapse } \\
\hline No & 525 & 83.20 & 458 & 83.88 & 67 & 78.82 & \multirow[t]{2}{*}{0.246} \\
\hline Yes & 106 & 16.80 & 88 & 16.12 & 18 & 21.18 & \\
\hline
\end{tabular}

Abbreviations: Antr, anthracyclines; BC, breast cancer; HER2, human epidermal growth factor receptor 2; IDC, invasive ductal carcinoma; ILC, invasive lobular carcinoma; $\mathrm{ISH}$, in situ hybridization; $\mathrm{pN}$, regional lymph node; $\mathrm{pT}$, primary tumor; Tax, taxanes; TNBC, triple-negative breast cancer.

with cancer recurrence as follows: for $\mathrm{Ki} 67<20 \%, 42.5 \%$ vs $54.1 \%$; for $\mathrm{Ki} 67$ 20\%-60\%, 52.8\% vs 40\%; and for $\mathrm{Ki} 67$ $>60 \%, 4.7 \%$ vs $5.9 \%$. Similarly, for CK5/6 negative, the proportions were $55.9 \%$ (19) vs 36.8\% (53) and for CK5/6 positive, they were $44.1 \%$ (15) vs $63.2 \%$ (91). Direct correlations were found between $\mathrm{CK} 5 / 6$ and $\mathrm{E}$-cad $(P<0.0001)$ and between CK5/6 and Cox-2 $(P=0.037)$.

In the specific TNBC population, significant or marginal correlations were revealed for CK5/6 $(P=0.010)$ and E-cad $(P=0.0016)$ with clinical stage, for EGFR with histopathological type ( $P=0.041)$, for p53 with the principally involved quadrant (external vs internal; $P=0.02$ ), for $\mathrm{Bcl} 2$ with menopausal status $(P=0.004)$ and BMI $(P=0.015)$, and for TOP2A with the in situ component $(P=0.013)$. Cox-2 positivity was marginally inversely correlated with capsular effraction $(P=0.046)$. The HER2 expression was correlated with histopathological type $(P=0.001)$ and lymphovascular invasion $(P=0.072)$, whereas Ki67 was correlated with pT $(P=0.004)$ and regional lymph node ( $\mathrm{pN} ; P=0.033$ ) (Tables 2 and 3$)$. The correlating biomarkers were CK5/6 and E-cad $(P=0.071)$.

\section{Clinical outcomes in relation to biomarkers}

In the general population, the mean follow-up was 55.7 months (range, 5-119), and relapse occurred in 106 patients $(16.8 \%)$. Only 18 of these $(2.8 \%)$ bore a triple-negative phenotype, representing $21.2 \%$ of this subgroup, and the remaining $88(83 \%)$ belonged to the non-TNBC subgroup, representing $16.1 \%$ of this conventional subpopulation $(P=0.246)$. Relapse was directly and significantly correlated with the clinical stage, grade $(\mathrm{G}), \mathrm{pN}(P<0.001)$, multicentric/multifocal aspect (MC/MF; $P=0.022)$, capsular effraction $(P=0.017)$, in situ component $(P=0.024)$, Ki67 $(P=0.051)$, and $\mathrm{CK} 5 / 6(P=0.041)$, and was predicted by
$\mathrm{MC} / \mathrm{MF}, \mathrm{G}$, and $\mathrm{CK} 5 / 6$. The mean estimated EFS was 99.6 months (95\% CI: 96.27-102.98), with 100.4 months (95\% CI: 96.83-103.95) in non-TNBC patients vs 85.52 months (95\% CI: 76.75-94.29) in TNBC patients ( $\mathrm{HR}=0.732 ; 95 \%$ CI: 0.441-1.216; $P=0.228$ ) (Figure 1).

Significant differences were observed according to the five surrogate intrinsic subgroups (Figure 2). ${ }^{7}$

In TNBC patients, relapse was significantly correlated with menopausal status $(P=0.016)$, Charlson index ( $P=0.065)$, BMI $(P=0.002), \mathrm{pN}(P=0.004)$, capsular effraction $(P=0.024)$, and $C K 5 / 6$ expression $(P=0.006)$. The estimated mean for EFS in CK5/6-negative patients (68.84 months [95\% CI: 50.06-87.63]) was significantly lower than that for CK5/6-positive patients (98.84 months [95\% CI: 87.99-109.69]) (HR=5.075; 95\% CI: 1.09-23.53; $P=0.038$; Figure 3). The log-rank tests for the differences between EFS and patients expressing vs those not expressing each of the other analyzed biomarkers were nonsignificant (Figure 3).

Significant differences $(P=0.006)$ between biomarker expression in relapsed vs non-relapsed TNBC patients were found only for CK5/6-negative (42.9\% [9] vs 57.1\% [12]) and CK5/6-positive (8\% [2] vs 92\% [23]) biomarkers. Within the relapsed population, patients were primarily $\mathrm{CK} 5 / 6$ negative (81.8\%), with a small CK5/6-positive group (18.2\%). Based on the CK5/6-related survival outcomes and CK5/6-E-cad correlation, a score build on $\mathrm{CK} 5 / 6$ and E-cad expression was applied, namely both CK5/6 negative and E-cad negative, either CK5/6 or E-cad negative and the counterpart biomarker positive, and CK5/6 positive and E-cad positive.

The estimated EFS in the group expressing none of the biomarkers was 39.64 months (95\% CI: 33.0-46.24) (HR $=2.09 ; 95 \%$ CI: $0.38-11.47 ; P=0.397), 64.23$ months in the group expressing either CK5/6 or E-cad $(95 \% \mathrm{CI}$ : 50.50-77.96) $(\mathrm{HR}=1.35 ; 95 \% \mathrm{CI}: 0.25-7.37 ; P=0.732)$, and 
Table 2 Correlation of CK5/6, EGFR, and E-cad with clinical and pathological variables in the TNBC population

\begin{tabular}{|c|c|c|c|c|c|c|c|c|c|}
\hline \multirow{3}{*}{$\begin{array}{l}\text { Variable/ } \\
\text { Biomarker }\end{array}$} & \multicolumn{2}{|l|}{ CK5/6 n (\%) } & \multirow[t]{3}{*}{$P$-value } & \multicolumn{2}{|l|}{ EGFR n (\%) } & \multirow[t]{3}{*}{$P$-value } & \multicolumn{2}{|l|}{ E-cad n (\%) } & \multirow[t]{3}{*}{$P$-value } \\
\hline & Negative & Positive & & Negative & Positive & & Negative & Positive & \\
\hline & $21(45.6 \%)$ & 25 (54.4\%) & & 27 (43.5\%) & 35 (54.5\%) & & $17(38.6 \%)$ & 27 (6I.4\%) & \\
\hline \multicolumn{10}{|l|}{ Quadrant } \\
\hline External & $8(38.1)$ & $16(64)$ & \multirow[t]{3}{*}{0.207} & $16(59.3)$ & I8 (5I.4) & \multirow[t]{3}{*}{0.808} & $9(52.9)$ & $14(5 \mid .9)$ & \multirow[t]{3}{*}{0.342} \\
\hline Internal & II (52.4) & $8(32)$ & & $10(37)$ & $15(42.9)$ & & $8(47.1)$ & $10(37)$ & \\
\hline Central & $2(9.5)$ & I (4) & & I (3.7) & $2(5.7)$ & & $0(0)$ & $3(11.1)$ & \\
\hline \multicolumn{10}{|l|}{ Clinical stage } \\
\hline 1 & $5(23.8)$ & $0(0)$ & \multirow[t]{3}{*}{0.010} & $3(11.1)$ & $2(5.7)$ & \multirow[t]{3}{*}{0.439} & 5 (29.4) & I (3.7) & \multirow[t]{3}{*}{0.016} \\
\hline II A, II B & $16(76.2)$ & $25(100)$ & & $24(88.9)$ & $33(94.3)$ & & $12(70.6)$ & $26(96.3)$ & \\
\hline III A, III B & $0(0)$ & $0(0)$ & & $0(0)$ & $0(0)$ & & $0(0)$ & $0(0)$ & \\
\hline \multicolumn{10}{|l|}{ Histopathology type } \\
\hline IDC & I8 (85.7) & $23(92)$ & \multirow[t]{4}{*}{0.495} & $27(100)$ & 30 (85.7) & \multirow[t]{4}{*}{0.041} & $15(88.2)$ & $24(88.9)$ & \multirow[t]{4}{*}{0.947} \\
\hline ILC & $0(0)$ & $0(0)$ & & $0(0)$ & $0(0)$ & & $0(0)$ & $0(0)$ & \\
\hline Mixed IDC/ILC & $3(14.3)$ & $2(8)$ & & $0(0)$ & $0(0)$ & & $0(0)$ & $0(0)$ & \\
\hline Other type & $0(0)$ & $0(0)$ & & $0(0)$ & $5(14.3)$ & & $2(11.8)$ & $3(11.1)$ & \\
\hline $\mathrm{pT}$ & & & & & & & & & \\
\hline pTla & \begin{tabular}{|l|}
$0(0)$ \\
\end{tabular} & $0(0)$ & 0.521 & $0(0)$ & \begin{tabular}{|l|}
$0(0)$ \\
\end{tabular} & 0.789 & $0(0)$ & $0(0)$ & 0.734 \\
\hline pTIb, pTIc & $8(38.1)$ & $6(26.1)$ & & $9(33.3)$ & $13(37.1)$ & & $6(40)$ & $8(29.6)$ & \\
\hline PT2 & $13(61.9)$ & $17(73.9)$ & & $18(66.7)$ & $20(57.1)$ & & $9(60)$ & $18(66.7)$ & \\
\hline PT3 & $0(0)$ & $0(0)$ & & $0(0)$ & $0(0)$ & & $0(0)$ & $0(0)$ & \\
\hline pT4 & $0(0)$ & $0(0)$ & & $0(0)$ & $0(0)$ & & $0(0)$ & $0(0)$ & \\
\hline Unknown & $0(0)$ & $0(0)$ & & $0(0)$ & $2(5.8)$ & & $0(0)$ & $\mathrm{I}(3.7)$ & \\
\hline MC/MF & & & & & & & & & \\
\hline No & $21(100)$ & $22(88)$ & 0.101 & 25 (92.6) & 32 (9I.4) & 0.867 & $15(88.2)$ & $25(92.6)$ & 0.624 \\
\hline Yes & $0(0)$ & $3(12)$ & & $2(7.4)$ & $3(8.6)$ & & $2(11.8)$ & $2(7.4)$ & \\
\hline Histologic grade & & & & & & & & & \\
\hline GI & $0(0)$ & $2(8)$ & 0.096 & $2(7.4)$ & $0(0)$ & 0.115 & $0(0)$ & $2(7.4)$ & 0.429 \\
\hline $\mathrm{G} 2$ & $6(28.6)$ & $2(8)$ & & $9(33.3)$ & $7(20)$ & & $3(17.6)$ & $6(22.2)$ & \\
\hline G3 & I5 (7I.4) & $21(84)$ & & $16(59.3)$ & 27 (77.I) & & I4 (82.4) & $18(66.7)$ & \\
\hline Unknown & $0(0)$ & $0(0)$ & & $0(0)$ & I (2.9) & & $0(0)$ & I (3.7) & \\
\hline $\mathrm{pN}$ & & & & & & & & & \\
\hline 0 & I5 (7I.4) & $14(56)$ & 0.277 & $17(63)$ & $22(62.9)$ & 0.178 & $10(58.8)$ & $18(66.7)$ & 0.354 \\
\hline $\mathrm{Ia}$ & $5(23.8)$ & $9(36)$ & & $10(37)$ & $8(22.9)$ & & $6(35.3)$ & $7(25.9)$ & \\
\hline $2 a$ & $0(0)$ & $2(8)$ & & $0(0)$ & 4 (II.4) & & $0(0)$ & $2(7.4)$ & \\
\hline $3 a$ & $\mathrm{I}(4.8)$ & $0(0)$ & & $0(0)$ & $\mathrm{I}(2.8)$ & & $\mathrm{I}(5.9)$ & $0(0)$ & \\
\hline Capsular effraction & & & & & & & & & \\
\hline No & $17(8 \mathrm{I})$ & $18(72)$ & 0.514 & $21(77.8)$ & 30 (85.7) & 0.417 & $14(82.4)$ & $22(8 I .5)$ & 0.942 \\
\hline Yes & $4(19)$ & $7(28)$ & & $6(22.2)$ & $5(14.3)$ & & $3(17.6)$ & $5(18.5)$ & \\
\hline Lymphovascular in & sion & & & & & & & & \\
\hline No & $19(90.5)$ & $21(84)$ & - & 25 (92.6) & \begin{tabular}{|l|}
$29(82.9)$ \\
\end{tabular} & 0.886 & I3 (86.4) & $22(8 \mid .5)$ & 0.285 \\
\hline Yes & $0(0)$ & $0(0)$ & & $2(7.4)$ & $2(5.7)$ & & $0(0)$ & $2(7.4)$ & \\
\hline Unknown & $2(9.5)$ & $4(16)$ & & $0(0)$ & 4 (II.4) & & $4(23.6)$ & $3(\mathrm{II} .1)$ & \\
\hline In situ pattern & & & & & & & & & \\
\hline No & 18 (85.7) & $22(88)$ & 0.252 & 25 (92.6) & $30(85.7)$ & 0.814 & $12(70.6)$ & $23(85.2)$ & 0.460 \\
\hline Yes & $3(14.3)$ & I (4) & & $2(7.4)$ & $3(8.6)$ & & $3(17.6)$ & $3(\mathrm{II} . \mathrm{I})$ & \\
\hline Unknown & $0(0)$ & $2(8)$ & & $0(0)$ & $2(5.7)$ & & $2(11.8)$ & I (3.7) & \\
\hline Relapse & & & & & & & & & \\
\hline No & $12(57.1)$ & $23(92)$ & 0.013 & $23(85.2)$ & $26(74.3)$ & 0.358 & $12(70.6)$ & $21(77.8)$ & 0.592 \\
\hline Yes & $9(42.9)$ & $2(8)$ & & $4(14.8)$ & $9(25.7)$ & & $5(29.4)$ & $6(22.2)$ & \\
\hline Total & 46 & & & 62 & & & 44 & & \\
\hline
\end{tabular}

Abbreviations: CK5/6, cytokeratin 5/6; E-cad, E-cadherin; IDC, invasive ductal carcinoma; ILC, invasive lobular carcinoma; MC/MF, multicentric/multifocal; pN, regional lymph node; PT, primary tumor; TNBC, triple-negative breast cancer. 


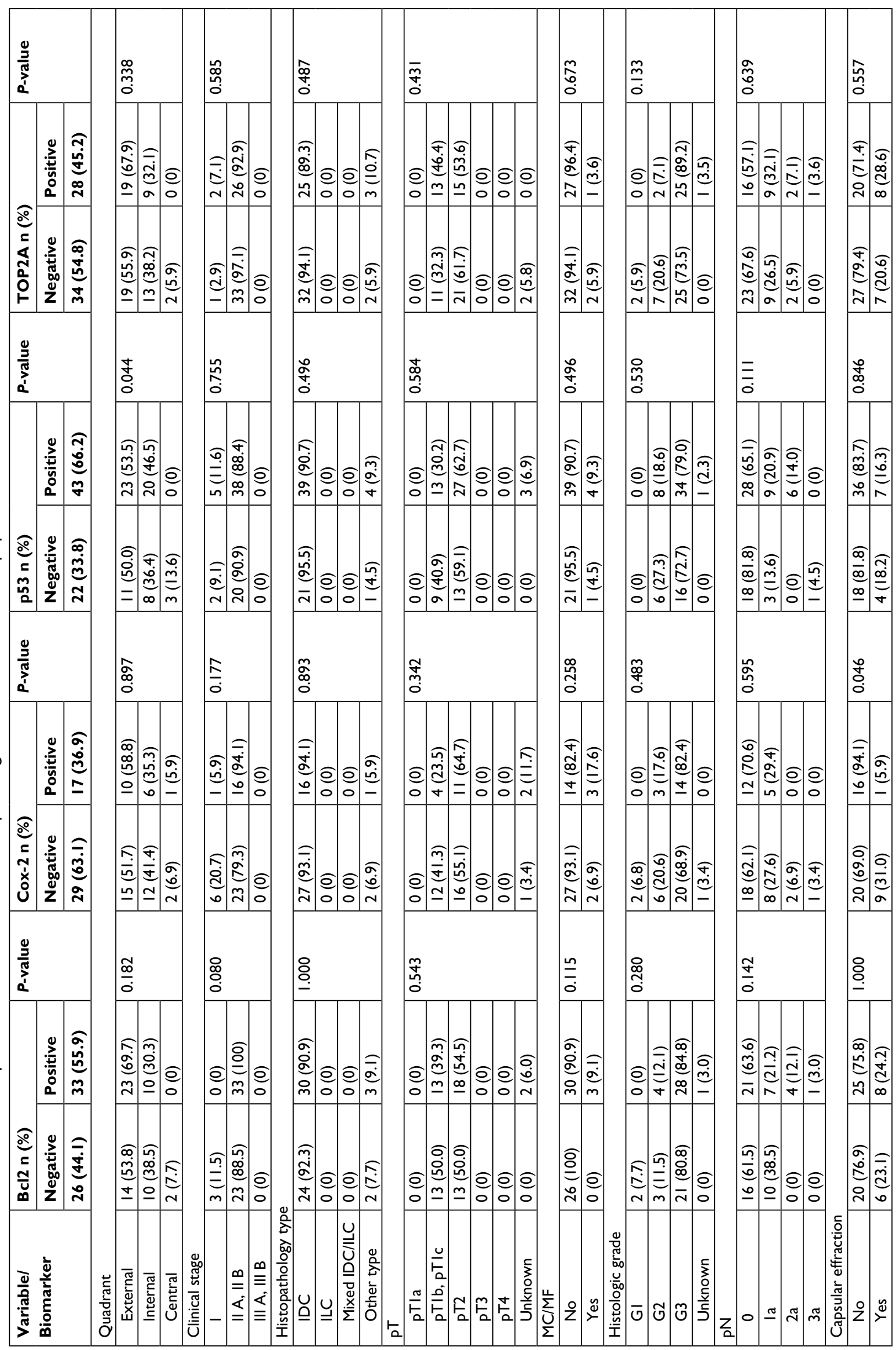




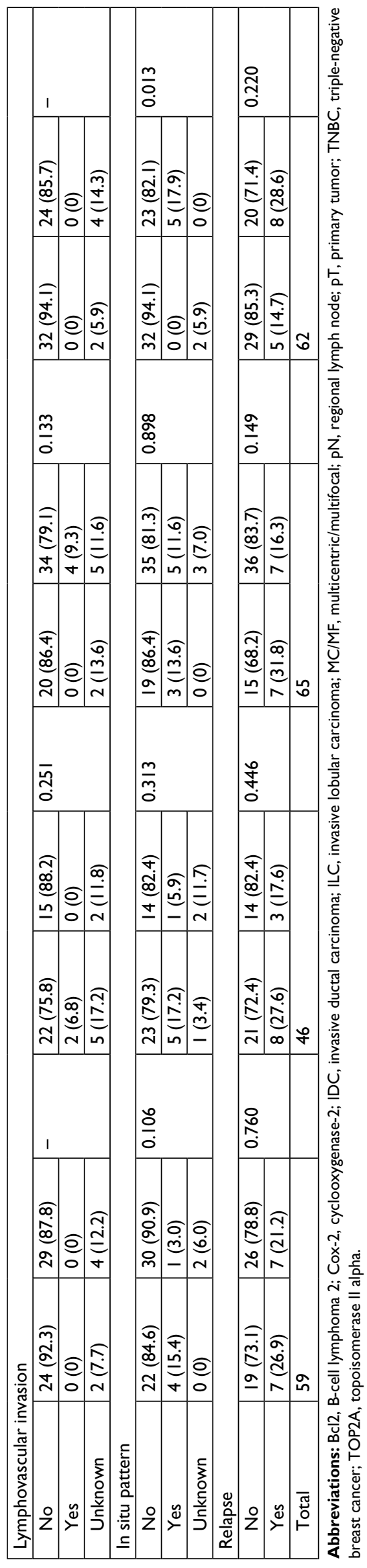

83.87 months in the group expressing both biomarkers ( $95 \%$ CI: 64.24-103.51; $P=0.667$ ) (Figure 4).

\section{Discussion}

Several biomarkers assessable by IHC techniques have been studied as prognostic factors in non-metastatic TNBC, as a single factor, in co-expression, or in a panel of multiple biomarkers. ${ }^{32,33}$ Well-known biomarkers, including cytokeratins (CK5/6, CK14, and CK17), EGFR, and the c-Kit receptor, are surrogates for the poor-prognostic basal-like subtypes, which represent $50 \%-80 \%$ of TNBC cases. ${ }^{34}$ Of recent interest are tumor infiltrating lymphocytes and androgen receptors (AR). ${ }^{35,36}$ Taken one by one or in association, either for the consecrated biomarkers or for the less well-known ones, the prognostic role is controversial.

Thus, Ki67, a non-histone nuclear protein measure of proliferation, is associated with a high probability of relapse and poor survival in early-stage breast cancer patients, regardless of $\mathrm{pN}$ status or adjuvant treatment. ${ }^{37,38}$ High levels of Ki67 were found to be directly related to TNBC tumor grade and size, and correlated with a higher rate of death. ${ }^{39}$ In our study, Ki67 was significantly correlated with the TNBC phenotype, the mean value being $44.7 \%$ vs $22.2 \%$ in non-TNBC patients. Ki67 was also correlated with advanced histopathological stage $(P=0.004)$ and nodal involvement $(P=0.033)$, with no difference in survival between patients with a score $\leq 20 \%$ in comparison with those $>20 \%$.

EGFR overexpression, one of the four members of the ErbB tyrosine kinase membrane receptor family that, through the Ras-Raf-MEK-ERK pathway regulates tumor cell growth, motility, and apoptosis, ${ }^{40}$ reaches $50 \%$ in TNBC (higher than in other breast cancer types) and approaches $90 \%$ in the basal-like subtype. ${ }^{34}$ Previous studies have found correlations between EGFR and poor prognosis features, such as large tumor size and high histopathological grade. ${ }^{41}$ In a retrospective study of 284 early-stage TNBC patients, EGFR positivity significantly correlated with poorer disease-free (DFS) and overall survival $(\mathrm{OS})(\mathrm{HR}=2.22 ; P=0.01$ and $\mathrm{HR}=2.19$; $P=0.03$, respectively) ${ }^{42}$ In our analysis, a borderline difference existed between EGFR expression in the TNBC and non-TNBC populations, with a paradoxical higher percentage of positivity in the latter subgroup. In TNBC patients, EGFR was more expressed in ductal carcinoma and was associated with shorter EFS compared with EGFR-negative patients (80 vs 92 months; $P=0.792$ ).

The transmembrane glycoprotein E-cad, encoded by the CDH1 gene, mediates epithelial cell-to-cell adhesion and plays an important role in cell proliferation and metastasis 


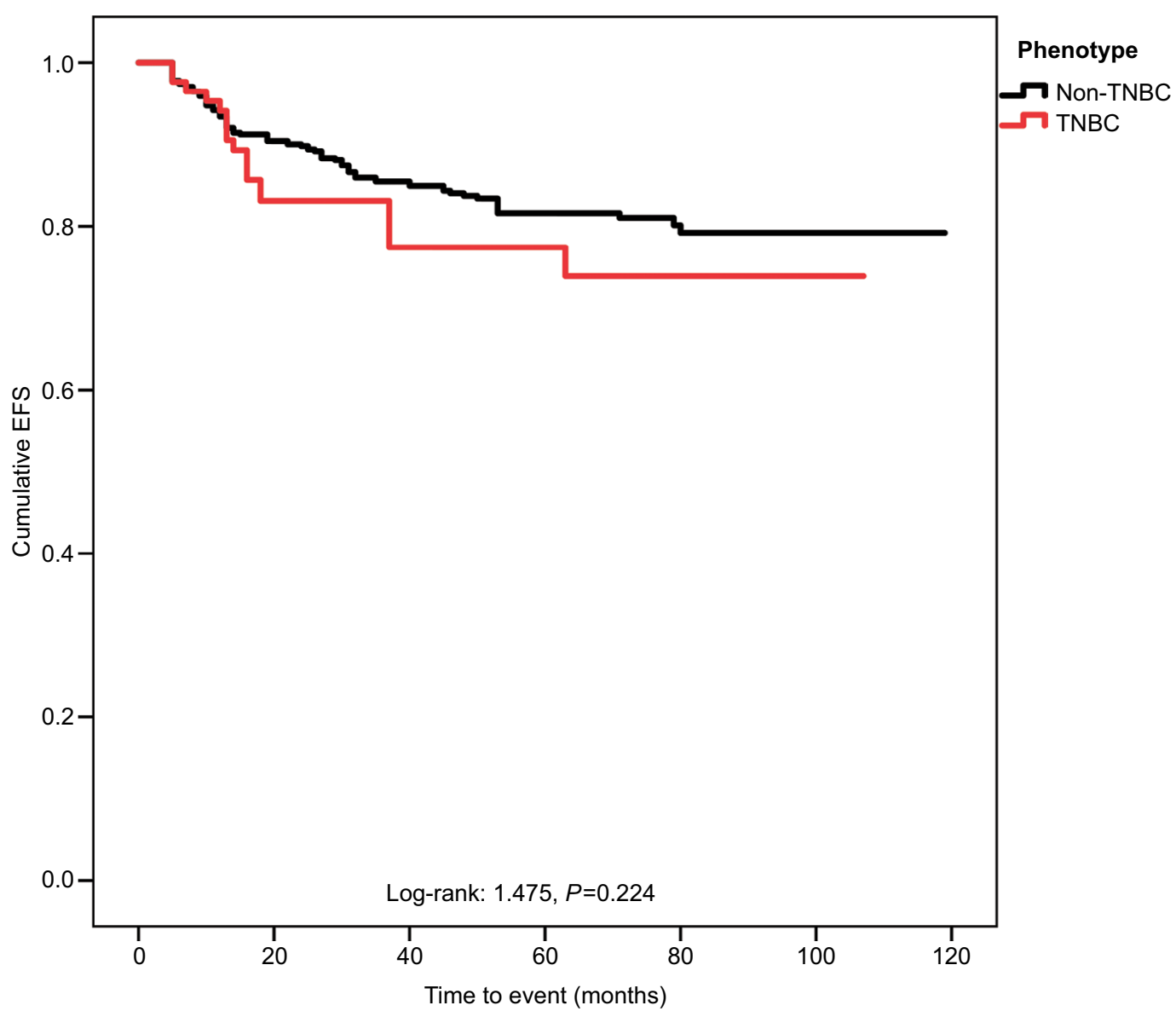

Figure I Kaplan-Meier curves in non-TNBC and TNBC subgroups.

Abbreviations: EFS, event-free survival; TNBC, triple-negative breast cancer.

suppression. ${ }^{43,44}$ E-cad negativity represents a surrogate marker for a lobular subtype of invasive breast carcinoma, but the absence of expression in non-lobular histology was found to be associated with large tumor size, metastatic lymph nodes, poor tumor differentiation, and the triple-negative phenotype. ${ }^{45,46} \mathrm{E}$-cad downregulation is a part of the epithelialto-mesenchymal transition mechanism associated with cancer invasiveness and metastasis reported in the claudin-low TNBC subtype, which has a high relapse rate. ${ }^{47,48}$ Thus, in 123 TNBC patients primarily treated by surgery, E-cad-negative cases displayed poorer outcomes regarding OS $(P=0.0265)$ and DFS $(P=0.0125) .{ }^{31}$ In another analysis $(\mathrm{N}=182)$, E-cad was preferentially negative in the basal-like subtype. ${ }^{49}$

In our study, negative E-cad staining was recorded in $38.6 \%$ (17 patients) of the TNBC population compared with $20.9 \%$ (27 patients) in the non-TNBC patient group $(P=0.020)$. E-cad positivity was inversely correlated with tumor grade $(P=0.016)$ and shows a tendency toward a longer mean EFS (85.74 vs 79.10 months in negative staining cases; $P=0.797)$.
Another biomarker apparently more specific than EGFR used to define the basal-like subtype is the high molecular weight basal CK5/6, whose detection by IHC is challenging because of focal and weak reactivity and no precise cutoff, with the percentages of positivity in TNBC varying in the literature from $24 \%$ to $72 \%{ }^{50,51} \mathrm{CK} 5 / 6$ correlates with necrosis and lymph node involvement. ${ }^{52,53}$ The overexpression of CK5/6 seems to correlate with HER2, Ki67, and p53 expressions. ${ }^{54}$ In a retrospective study of a non-metastatic population $(\mathrm{N}=97)$, the recurrence risk and mortality rate were 2.41 -fold $(P=0.027)$, but 3.74 -fold higher $(P=0.01)$ in CK5/6-positive patients. ${ }^{55}$ Conversely, in a small sample $(\mathrm{N}=53)$ of TNBC patients, CK5/6 expression was associated with more favorable outcomes than CK5/6 negativity (HR for $\mathrm{RFS}=0.23, P<0.01$; HR for $\mathrm{OS}=0.39, P=0.02) .{ }^{56}$

In our study of TNBC patients, CK5/6 expression was correlated with the clinical stage $(P=0.010)$, and there was no correlation with lymph node involvement. CK5/6 was the only biomarker associated with relapse $(P=0.006)$, and the estimated mean EFS in CK5/6-negative patients (68.84 


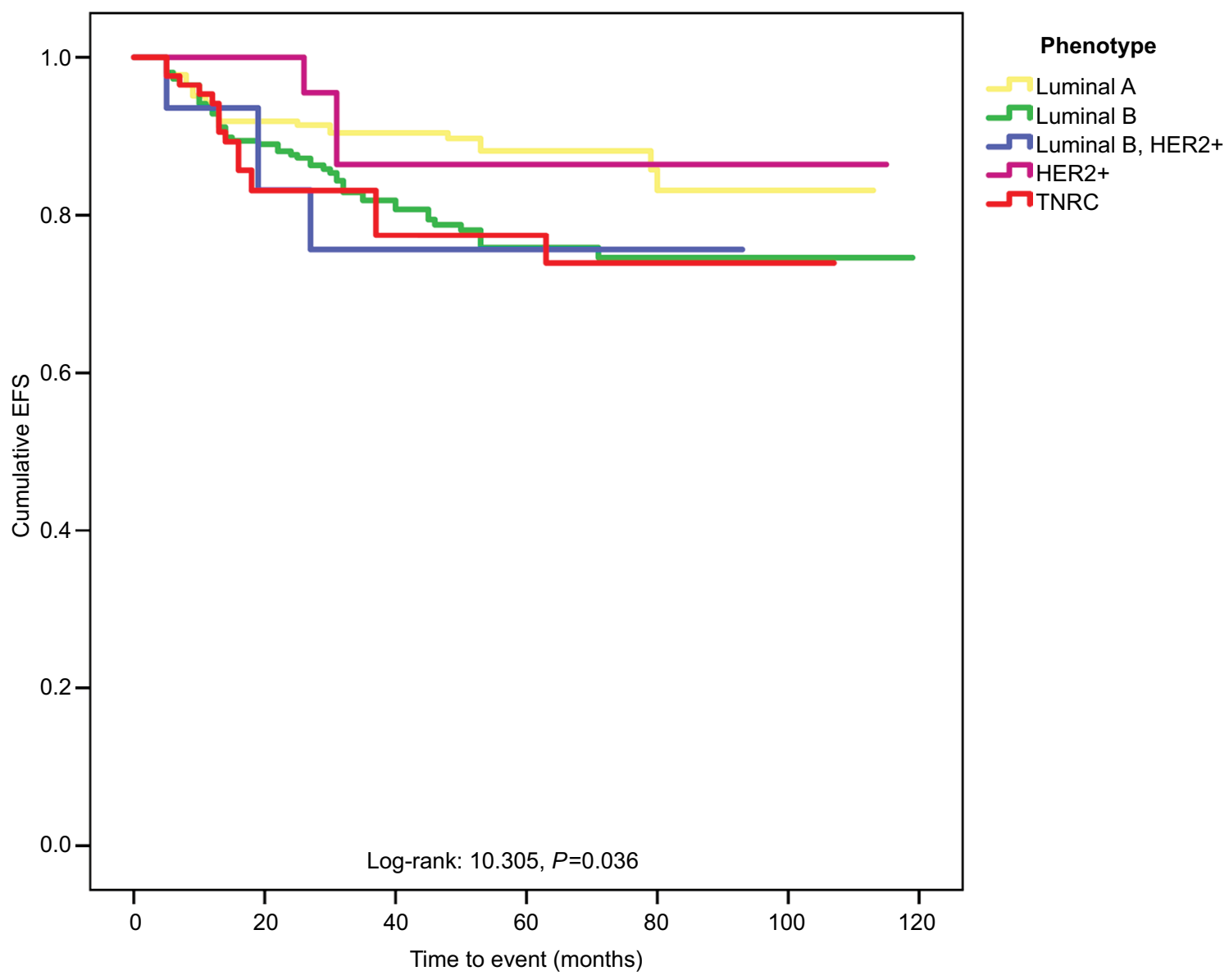

Figure 2 Kaplan-Meier curves in $\mathrm{IHC}$ surrogate phenotypes $\mathrm{BC}$ population.

Abbreviations: BC, breast cancer; EFS, event-free survival; HER2, human epidermal growth factor receptor 2; IHC, immunohistochemical; TNBC, triple-negative breast cancer.

months) was inferior to that of CK5/6-positive patients $(98.84$ months) $(P=0.038)$.

TP53 is a tumor suppressor gene that encodes the p53 protein and participates in cell cycle progression, apoptosis regulation, and DNA repair. ${ }^{57}$ Missense mutations can lead to stabilization of the $\mathrm{p} 53$ protein that is oncogenic and accumulates in the cytoplasm, thus becoming detectable by IHC techniques. ${ }^{58,59}$ In breast cancer, the frequency of mutation has been reported to be as high as $30 \%$, whereas in the triple-negative phenotype, it reaches $70 \%$ and about $95 \%$ in the basal-like subtype. ${ }^{60-62}$ p53 positivity is directly correlated with lymph node involvement, tumor size and grade, lymphatic invasion, and EGFR overexpression. ${ }^{62,63}$ High p53 levels are also associated with a high Ki67 score. ${ }^{64}$ p53 overexpression was found in most analyses to be associated with poor outcomes in TNBC patients. ${ }^{65}$ However, in a small sample of early-stage TNBC patients $(\mathrm{N}=32)$, p53-positive status was an independent predictive factor for a shorter survival span (5.4 relative risk for RFS; $P=0.013) .{ }^{66}$ In other ways, p53 microarray positivity was associated with a better survival rate (142 node-negative TNBC patients), the HR for DFS being 0.52 (95\% CI: $0.27-0.97 ; P=0.004)$, with a $20.9 \%$ relapse rate vs $37.5 \%$ in p53-negative patients. ${ }^{67}$

In our analysis, p53 was one of the few biomarkers with a significantly different expression $(P<0.0001)$ in TNBC patients compared with non-TNBC patients $(66.2 \%, 43$ patients vs $32.5 \%, 113$ patients). The risk of relapse was higher, albeit not significantly, in p53-negative patients (HR $=1.99 ; 95 \%$ CI: 0.699-5.690; $P=0.197)$. As it is unclear whether p53 expression reflects the wild-type or mutant TP53, our results confirm those of others.

Among the less assessed biomarkers in breast cancer is the $\mathrm{Bcl} 2$ protein, an antiapoptotic protein, by participates to the $\mathrm{G}_{0}$ cell cycle prolongation. ${ }^{68} \mathrm{Bcl} 2$ 's tumorigenic potential of inappropriate expression is in contrast to human follicular B cell non-Hodgkin's lymphoma and is associated with 


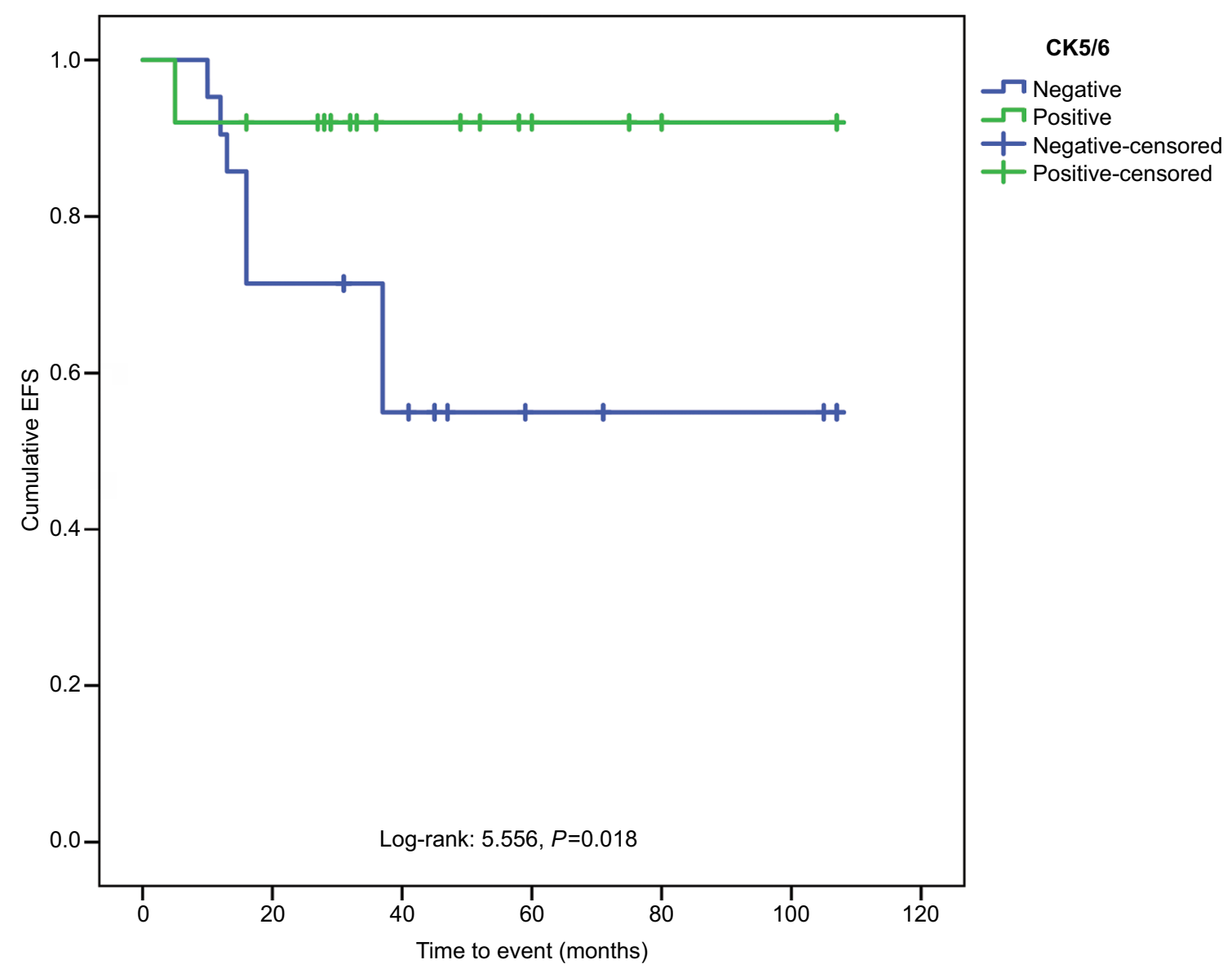

Figure 3 Kaplan-Meier curves according to the CK5/6 expression in TNBC patients.

Abbreviations: $\mathrm{CK} 5 / 6$, cytokeratin 5/6; EFS, event-free survival; TNBC, triple-negative breast cancer.

improved outcomes in hormone receptor-positive nodenegative breast cancer, as it is one of 21 genes validated in the prognostic signature, Oncotype DX (Genomic Health Inc, Redwood City, CA, USA) ${ }^{69,70}$ In a large cohort analysis of 11,212 women with early-stage breast cancer, Bcl2 expression was found to be a powerful positive prognostic marker in the ER-negative subgroup, independent of adjuvant therapy $(\mathrm{HR}=0.63 ; P=0.001) .{ }^{71}$ In 635 early-stage TNBC patients, Bcl2-negative status was associated with a double risk of recurrence $(\mathrm{HR}=2.45 ; P=0.00002$ ) and significantly correlated with high tumor grade and high levels of HER3 and E-cad expression $(P<0.001) .{ }^{72}$ Conversely, in a small cohort of triple-negative $(\mathrm{N}=124)$ vs non-triple-negative $(\mathrm{N}=458)$ patients, Bcl2 expression was a predictor for poor survival $(P=0.028) .{ }^{73}$ Our Bcl2-negative patients in the TNBC group had a poorer outcome (78.79 months; $95 \%$ CI: 63.64-93.95) than those in the Bcl2-positive group ( 86.43 months; $95 \% \mathrm{CI}$ : 72.91-99.95), although the difference did not reach statistical significance ( $\mathrm{HR}=1.19 ; 95 \% \mathrm{CI}$ : 0.42-3.39; $P=0.746$ ).
TOP2A protein catalyzes the breakage and reunion of double-stranded DNA, and its tumor cell staining is correlated with TOP $2 A$ gene aberrations, situated on chromosome $17 \mathrm{q} 12-\mathrm{q} 21 .{ }^{74} \mathrm{Few}$ studies address the question of its prognostic significance in TNBC and the results are inconclusive. ${ }^{75}$ TOP2A expression was found to be twice as high in breast tumors expressing basal cytokeratins and correlated with a high tumor grade and high Ki67 score. ${ }^{76}$ Along these lines, in one retrospective study of 145 early-stage TNBC patients, TOP2A positivity was marginally associated with a shorter time to progression $(\mathrm{HR}=2.01 ; P=0.059) \cdot{ }^{77}$

In our 62 TNBC tumor specimens assessed for TOP2A expression, a direct correlation was found with the in situ pattern $(P=0.003)$. Survival without relapse seemed shorter in TOP2A-positive than in TOP2A-negative patients (mean EFS, 74.86 vs 93.21 months; $P=0.151$ ).

The Cox proteins (prostaglandin $\mathrm{H} 2$ syntheses) are membrane-bound enzymes and members of the mammalian heme-dependent peroxidase family that catalyze the 




Figure 4 Kaplan-Meier curves in subgroups according to the CK5/6-E-cad score in TNBC patients.

Abbreviations: CK5/6, cytokeratin 5/6; E-cad, E-cadherin; Neg, negative; Pos, positive; TNBC, triple-negative breast cancer.

conversion of arachidonic acid released from membrane phospholipids to prostaglandin $\mathrm{H} 2$ and reactive oxygen species. ${ }^{78}$ Cox-2 is normally found at a very low level in most tissues and is highly inducible by tumor promoters. It is amplified in breast carcinoma cells in about $30 \%$ of cases, appearing to be correlated with ER expression, lymph node involvement, high histological grade, and, in some studies, HER2 overexpression and high Ki67 or p53 scores. ${ }^{79-81}$ In ER-negative breast tumors, Cox-2 appears to play a role in neo-angiogenesis, and thus its expression is considered to be a negative prognostic factor. ${ }^{82}$ In our TNBC patients, Cox-2 expression was inversely correlated with capsular effraction $(P=0.046)$, thus appearing as a favorable prognostic factor. Hence, the mean estimated EFS was lower in Cox-2-negative patients, that is 79.35 months compared with 90.41 months in cases expressing the biomarker $(P=0.547)$.

The last part of our discussion, on the analyzed biomarkers, focuses on HER2, the transmembrane glycoprotein with intracellular tyrosine kinase activity belonging to the EGFR family, which becomes active by homo- and heterodimerization, by which HER2-HER3 plays an important role in carcinogenesis through the activation of the PI3K/ protein kinase $\mathrm{B} /$ mammalian target of the rapamycin pathway. ${ }^{83,84}$ HER 2 overexpression has been found in $~ 13 \%-23 \%$ of breast cancers and is associated with poor survival..$^{85}$ According to the $2015 \mathrm{St}$ Gallen recommendations and ASCO and CAP guidelines, the HER2 IHC staining score in the triple-negative phenotype could be 0 or $1+$ or equivocal (2+) and negative according to the ISH test. The ERBB2 gene copy is closely associated with HER2 protein expression, but studies show that only around $20 \%$ of tumors with positive immunostaining in $\leq 50 \%$ of cells showed gene amplification compared with $85.7 \%$ of tumors presenting positive staining in $>50 \%$ of cells. ${ }^{7,10,11,86}$

Therefore, it is highly probable that the triple-negative phenotype bearing an amplified ERBB2 gene would not have the same clinical behavior as a tumor without staining or with incomplete staining in $<10 \%$ of the tumor cells. In breast cancer, HER2 overexpression is an independent negative prognostic factor directly correlated with tumor 
grade and lymph node involvement and inversely correlated with ER expression. ${ }^{87}$ Not many studies addressed the question of clinical relevance of HER2 score in nonmetastatic triple negative breast cancer population and the results are inconclusive. In 119 non-metastatic TNBCs, patients with a HER2-neu score of 0 had a significantly poorer outcome in terms of DFS and OS compared with those with a HER2 score of 1 or $2(P=0.0021, P=0.0105) .{ }^{88}$ In our previous analysis of 47 patients with early-stage TNBC, we found the median EFS to be shorter in the HER2-positive, ISH-negative cases (29.2 months) than in the HER2-negative ones (31.8 months), without reaching significance $(P=0.9){ }^{89}$

In our triple-negative patients, HER2 expression was marginally correlated with lymphovascular invasion $(P=0.072)$ and significantly with histopathological type $(P=0.001)$. In relapsed patients, some differences existed in HER2 expression: $88.9 \%$ (16 patients) were negative and $11.1 \%$ had weak expression $(P=0.559)$ with no significant differences between the mean EFS of the subgroups.

Of the biomarkers examined in the present study, only EGFR was found to be significantly directly correlated with the triple-negative phenotype. In the literature, EGFR and CK5/6 co-expression are described in approximately half of triple-negative tumors, as they stand for the poor prognostic basal-like subtype. ${ }^{34,90}$ Regarding less specific biomarkers, TNBC appeared to be associated with p53 expression and high Ki67 levels in $>50 \%$ of cases. ${ }^{91}$

As for outcomes, the only biomarker whose expression was inversely correlated with relapse in our specific population was that of $\mathrm{CK} 5 / 6$. Patients considered to be CK5/6 negative had five times higher risk of relapse than those displaying biomarker expression. Lastly, for our target population, we proposed a prognostic score based on CK5/6 and E-cad expression, but the differences between the identified subgroups did not reach statistical significance. Among previous scores assessing roughly the same types of IHC biomarkers in non-metastatic TNBC patients is the study of Kashiwagi et al, who evaluated the prognostic role of E-cad and Ki67 in 138 triple-negative patients undergoing adjuvant chemotherapy. The combination of E-cad negative and high Ki67 was associated with worse OS $(P<0.001){ }^{92}$ In another study of E-cad, AR, and Ki67 expression in a small cohort $(\mathrm{N}=45)$ of primary operable TNBC patients, AR-negative and Ki67-positive patients had a significantly poorer OS $(P=0.0202) .{ }^{49}$ In 102 Japanese patients with invasive TNBC who underwent primary surgery, analysis of the prognostic role of histological factors, such as pathological tumor size and nodal status, along with basal-like specific marker expression (EGFR, CK5/6, CK14, and CK35), led to the creation of three leader scores, of which the three groups of patients had statistically different risks of relapse and breast cancer-specific deaths, respectively. ${ }^{93}$ In a recent analysis of 99 cases of TNBC, CK5/6 expression was inversely correlated with $\mathrm{AR}$ and Ki67 levels, and it was associated with a better outcome than for $\mathrm{CK} 5 / 6$-negative patients $(\mathrm{HR}=0.39$; $P=0.02)$. Moreover, E-cad expression was found to be an independent favorable prognostic biomarker $(P=0.05) .{ }^{56}$

In agreement with these results, the population that expressed both biomarkers in our study displayed the longest EFS, whereas those that did not express any biomarker showed the poorest outcomes. This finding might be explained by the absence of differences in CK5/6 expression in triple-negative compared with non-triple-negative patients as well as because there is no established cutoff for $\mathrm{CK} 5 / 6$ positivity. Furthermore, in several studies, the threshold was $1 \%$, whereas our cutoff of $10 \%$ was fixed by the institutional internal laboratory. The participation of E-cad in our score as a good prognostic biomarker is as expected, as the absence of expression was found to be associated with poorer outcomes in other studies, ${ }^{32}$ seemingly correlated with the basal-like subtype. ${ }^{49}$

\section{Conclusion}

Given the published research, our preliminary analyses were designed to investigate a plethora of biomarkers correlated with various clinical and histopathological prognostic factors, but whose correlations with relapse or survival without relapse had not yet been confirmed. Due to the small number of TNBC patients and even smaller number of those patients tested for each biomarker, the results in our study were often statistically insignificant.

Other teams have assessed several scores to identify patients with good prognoses within this population, but none of them has yet been validated. Each of our score component biomarkers ( $\mathrm{CK} 5 / 6$ and E-cad) has been assessed as a constituent of such scores, but to our knowledge, these two have not been assessed solely together.

Other limitations of our study include the lack of standardization for the IHC assessment of biomarkers, other than the assessment of hormone receptors or HER2, and lack of guidelines for interpretation and reproducibility, which leads to discordant results.

We will add inferential statistical tests to identify other factors that might be included in our score. The final analysis will also contain the application of the score in borderline tumors, such as ER 1\%-10\%, PR 1\%-10\%, and non-expressing HER2 population, to identify the subgroups of very bad prognoses. 


\section{Acknowledgment}

We would like to thank Mr Everardo D Saad for his written contribution and $\mathrm{Mr}$ Sorin $\mathrm{S}$ Opris for his assistance in preparing the article.

\section{Disclosure}

The authors report no conflicts of interest in this work.

\section{References}

1. Forouzanfar MH, Foreman KJ, Delossantos AM, et al. Breast and cervical cancer in 187 countries between 1980 and 2010: a systematic analysis. Lancet. 2011;378(9801):1461-1484.

2. Prat A, Perou CM. Deconstructing the molecular portraits of breast cancer. Mol Oncol. 2011;5(1):5-23.

3. Sørlie T, Perou CM, Tibshirani R, et al. Gene expression patterns of breast carcinomas distinguish tumor subclasses with clinical implications. Proc Natl Acad Sci U S A. 2001;98(19):10869-10874.

4. Parker JS, Mullins M, Cheang MC, et al. Supervised risk predictor of breast cancer based on intrinsic subtypes. J Clin Oncol. 2009;27(8):1160-1167.

5. Bastien RR, Rodríguez-Lescure Á, Ebbert MT, et al. PAM50 breast cancer subtyping by RT-qPCR and concordance with standard clinical molecular markers. BMC Med Genomics. 2012;5:44.

6. Voduc KD, Cheang MC, Tyldesley S, Gelmon K, Nielsen TO, Kennecke $\mathrm{H}$. Breast cancer subtypes and the risk of local and regional relapse. J Clin Oncol. 2010;28(10):1684-1691.

7. Coates AS, Winer EP, Goldhirsch A, et al; American Society of Clinical Oncology; College of American Pathologists. Tailoring therapiesimproving the management of early breast cancer: St Gallen International Expert Consensus on the Primary Therapy of Early Breast Cancer 2015. Ann Oncol. 2015;26(8):1533-1546.

8. Foulkes WD, Smith IE, Reis-Filho JS. Triple-Negative Breast Cancer. N Engl J Med. 2010;363(20):1938-1948.

9. Hammond ME, Hayes DF, Dowsett M, et al. American Society of Clinical Oncology/College of American Pathologists guideline recommendations for immunohistochemical testing of estrogen and progesterone receptors in breast cancer. Arch Pathol Lab Med. 2010;134(6):907-922.

10. Wolff AC, Hammond ME, Schwartz JN, et al; American Society of Clinical Oncology; College of American Pathologists. American Society of Clinical Oncology/College of American Pathologists guideline recommendations for human epidermal growth factor receptor 2 testing in breast cancer. J Clin Oncol. 2007;25(1):118-145.

11. Irvin WJ Jr, Carey LA. What is triple-negative breast cancer? Eur $J$ Cancer. 2008;44(18):2799-2805.

12. Lin NU, Vanderplas A, Hughes ME, et al. Clinicopathologic features, patterns of recurrence, and survival among women with triple-negative breast cancer in the National Comprehensive Cancer Network. Cancer. 2012;118(22):5463-5472.

13. Smid M, Wang Y, Zhang Y, et al. Subtypes of breast cancer show preferential site of relapse. Cancer Res. 2008;68(9):3108-3114.

14. Dent R, Trudeau M, Pritchard KI, et al. Triple-negative breast cancer: clinical features and patterns of recurrence. Clin Cancer Res. 2007;13(15 Pt 1):4429-4434.

15. Kaplan HG, Malmgren JA, Atwood M. T1N0 triple negative breast cancer: risk of recurrence and adjuvant chemotherapy. Breast $J$. 2009;15(5):454-460.

16. Podo F, Buydens LM, Degani H, et al; FEMME Consortium. Triplenegative breast cancer: present challenges and new perspectives. Mol Oncol. 2010;4(3):209-229.

17. Alvarez RH, Valero V, Hortobagyi GN. Emerging targeted therapies for breast cancer. J Clin Oncol. 2010;28(20):3366-3379.

18. Senkus E, Kyriakides S, Penault-Llorca F, et al; ESMO Guidelines Working Group. Primary breast cancer: ESMO Clinical Practice Guidelines for diagnosis, treatment and follow-up. Ann Oncol. 2013;24 Suppl 6:vi7-vi23.
19. NCCN. NCCN guidelines. Breast cancer, version 3; 2017. Available from: http://www.nccn.org/professionals/physician_gls/pdf/breast.pdf. Accessed March 2, 2017.

20. Haffty BG, Yang Q, Reiss M, et al. Locoregional relapse and distant metastasis in conservatively managed triple negative early-stage breast cancer. J Clin Oncol. 2006;24(36):5652-5657.

21. Trendell-Smith NJ, Peston D, Shousha S. Adenoid cystic carcinoma of the breast: a tumour commonly devoid of oestrogen receptors and related proteins. Histopathology. 1999;35(3):241-248.

22. Lehmann BD, Bauer JA, Chen X, et al. Identification of human triplenegative breast cancer subtypes and preclinical models for selection of targeted therapies. J Clin Invest. 2011;121(7):2750-2767.

23. Pusztai L. Gene expression profiling of breast cancer. Breast Cancer Res. 2009;11 Suppl(3):S11.

24. Bertucci F, Finetti P, Cervera N, et al. How basal are triple-negative breast cancers? Int J Cancer. 2008;123(1):236-240.

25. Badve S, Dabbs DJ, Schnitt SJ, et al. Basal-like and triple-negative breast cancers: a critical review with an emphasis on the implications for pathologists and oncologists. Mod Pathol. 2011;24(2):157-167.

26. Choo JR, Nielsen TO. Biomarkers for Basal-like Breast Cancer. Cancers (Basel). 2010;2(2):1040-1065.

27. Rakha EA, El-Sayed ME, Green AR, Lee AH, Robertson JF, Ellis IO. Prognostic markers in triple-negative breast cancer. Cancer. 2007;109(1):25-32.

28. Edge SB, Compton CC. The American Joint Committee on Cancer: the 7 th edition of the AJCC cancer staging manual and the future of TNM. Ann Surg Oncol. 2010;17(6):1471-1474.

29. Elston CW, Ellis IO. Pathological prognostic factors in breast cancer. I. The value of histological grade in breast cancer: experience from a large study with long-term follow-up. Histopathology. 1991;19(5):403-410.

30. Rosen PP, Saigo PE, Braun DW Jr, Weathers E, DePalo A. Predictors of recurrence in stage I (T1N0M0) breast carcinoma. Ann Surg. 1981;193(1):15-25.

31. Bradburn MJ, Clark TG, Love SB, Altman DG. Survival analysis Part III: multivariate data analysis -- choosing a model and assessing its adequacy and fit. Br J Cancer. 2003;89(4):605-611.

32. Kashiwagi S, Yashiro M, TakashimaT, et al. Significance of E-cadherin expression in triple-negative breast cancer. Br J Cancer. 2010;103(2):249-255.

33. Won JR, Gao D, Chow C, et al. A survey of immunohistochemical biomarkers for basal-like breast cancer against a gene expression profile gold standard. Mod Pathol. 2013;26(11):1438-1450.

34. Nielsen TO, Hsu FD, Jensen K, et al. Immunohistochemical and clinical characterization of the basal-like subtype of invasive breast carcinoma. Clin Cancer Res. 2004;10(16):5367-5374.

35. Adams S, Gray RJ, Demaria S, et al. Prognostic value of tumor-infiltrating lymphocytes in triple-negative breast cancers from two phase III randomized adjuvant breast cancer trials: ECOG 2197 and ECOG 1199. J Clin Oncol. 2014;32(27):2959-2966.

36. Wang C, Pan B, Zhu H, et al. Prognostic value of androgen receptor in triple negative breast cancer: A meta-analysis. Oncotarget. 2016;7(29):46482-46491.

37. Urruticoechea A, Smith IE, Dowsett M. Proliferation marker Ki-67 in early breast cancer. J Clin Oncol. 2005;23(28):7212-7220.

38. de Azambuja E, Cardoso F, de Castro G Jr, et al. Ki-67 as prognostic marker in early breast cancer: a meta-analysis of published studies involving 12,155 patients. Br J Cancer. 2007;96(10):1504-1513.

39. Wang W, Wu J, Zhang P, et al. Prognostic and predictive value of Ki-67 in triple-negative breast cancer. Oncotarget. 2016;7(21):31079-31087.

40. Yarden Y, Sliwkowski MX. Untangling the ErbB signalling network. Nat Rev Mol Cell Biol. 2001;2(2):127-137.

41. Siziopikou KP, Ariga R, Proussaloglou KE, Gattuso P, Cobleigh M. The challenging estrogen receptor-negative/ progesterone receptor-negative/ HER-2-negative patient: a promising candidate for epidermal growth factor receptor-targeted therapy? Breast J. 2006;12(4):360-362.

42. Viale G, Rotmensz N, Maisonneuve P, et al. Invasive ductal carcinoma of the breast with the "triple-negative" phenotype: prognostic implications of EGFR immunoreactivity. Breast Cancer Res Treat. 2009;116(2):317-328. 
43. Andrews JL, Kim AC, Hens JR. The role and function of cadherins in the mammary gland. Breast Cancer Res. 2012;14(1):203.

44. Gumbiner BM. Regulation of cadherin-mediated adhesion in morphogenesis. Nat Rev Mol Cell Biol. 2005;6(8):622-634.

45. Baranwal S, Alahari SK. Molecular mechanisms controlling E-cadherin expression in breast cancer. Biochem Biophys Res Commun. 2009;384(1):6-11.

46. Gould Rothberg BE, Bracken MB. E-cadherin immunohistochemical expression as a prognostic factor in infiltrating ductal carcinoma of the breast: a systematic review and meta-analysis. Breast Cancer Res Treat. 2006;100(2):139-148.

47. Thiery JP. Epithelial-mesenchymal transitions in tumour progression. Nat Rev Cancer. 2002;2(6):442-454.

48. Prat A, Parker JS, Karginova O, et al. Phenotypic and molecular characterization of the claudin-low intrinsic subtype of breast cancer. Breast Cancer Res. 2010;12(5):R68.

49. Mahler-Araujo B, Savage K, Parry S, Reis-Filho JS. Reduction of E-cadherin expression is associated with non-lobular breast carcinomas of basal-like and triple negative phenotype. J Clin Pathol. 2008;61(5):615-620.

50. Cheang MC, Voduc D, Bajdik C, et al. Basal-like breast cancer defined by five biomarkers has superior prognostic value than triple-negative phenotype. Clin Cancer Res. 2008;14(5):1368-1376.

51. Pintens S, Neven P, Drijkoningen M, et al. Triple negative breast cancer: a study from the point of view of basal CK5/6 and HER-1.J Clin Pathol. 2009;62(7):624-628.

52. Rao C, Shetty J, Prasad KH. Immunohistochemical profile and morphology in triple - negative breast cancers. J Clin Diagn Res. 2013;7(7):1361-1365.

53. Sutton LM, Han JS, Molberg KH, et al. Intratumoral expression level of epidermal growth factor receptor and cytokeratin $5 / 6$ is significantly associated with nodal and distant metastases in patients with basal-like triple-negative breast carcinoma. Am J Clin Pathol. 2010;134(5):782-787.

54. Kutomi G, Ohmura T, Suzuki Y, Hirata K. History and future of surgical treatment. Nihon Rinsho. 2012;70 Suppl(7):13-17. Japanese.

55. Inanc M, Ozkan M, Karaca $\mathrm{H}$, et al. Cytokeratin 5/6, c-Met expressions, and PTEN loss prognostic indicators in triple-negative breast cancer. Med Oncol. 2014;31(1):801.

56. Adamo B, Ricciardi GRR, Ieni A, et al. The prognostic significance of combined androgen receptor, E-Cadherin, Ki67 and CK5/6 expression in patients with triple negative breast cancer. Oncotarget. 2017;8(44):76974-76986.

57. Lacroix M, Toillon RA, Leclercq G. p53 and breast cancer, an update. Endocr Relat Cancer. 2006;13(2):293-325.

58. Tsuda $\mathrm{H}$, Hirohashi S. Association among p53 gene mutation, nuclear accumulation of the $\mathrm{p} 53$ protein and aggressive phenotypes in breast cancer. Int J Cancer. 1994;57(4):498-503.

59. Soussi T, Béroud C. Assessing TP53 status in human tumours to evaluate clinical outcome. Nat Rev Cancer. 2001;1(3):233-240.

60. Olivier M, Langerød A, Carrieri P, et al. The clinical value of somatic TP53 gene mutations in 1,794 patients with breast cancer. Clin Cancer Res. 2006;12(4):1157-1167.

61. Cancer Genome Atlas Network. Comprehensive molecular portraits of human breast tumours. Nature. 2012;490(7418):61-70.

62. Gajdos C, Tartter PI, Bleiweiss IJ. Lymphatic invasion, tumor size, and age are independent predictors of axillary lymph node metastases in women with T1 breast cancers. Ann Surg. 1999;230(5):692-696.

63. Ding L, Ellis MJ, Li S, et al. Genome remodelling in a basal-like breast cancer metastasis and xenograft. Nature. 2010;464(7291):999-1005.

64. Pan Y, Yuan Y, Liu G, Wei Y. P53 and Ki-67 as prognostic markers in triple-negative breast cancer patients. PLoS One. 2017;12(2):e0172324.

65. Biganzoli E, Coradini D, Ambrogi F, et al. p53 status identifies two subgroups of triple-negative breast cancers with distinct biological features. Jpn J Clin Oncol. 2011;41(2):172-179.

66. Coates AS, Millar EK, O'Toole SA, et al. Prognostic interaction between expression of $\mathrm{p} 53$ and estrogen receptor in patients with node-negative breast cancer: results from IBCSG Trials VIII and IX. Breast Cancer Res. 2012;14(6):R143.
67. Chae BJ, Bae JS, Lee A, et al. p53 as a specific prognostic factor in triple-negative breast cancer. Jpn J Clin Oncol. 2009;39(4):217-224.

68. Basu A, Haldar S. The relationship between BcI2, Bax and p53: consequences for cell cycle progression and cell death. Mol Hum Reprod. 1998;4(12):1099-1109.

69. Tsujimoto Y, Finger LR, Yunis J, Nowell PC, Croce CM. Cloning of the chromosome breakpoint of neoplastic B cells with the $t(14 ; 18)$ chromosome translocation. Science. 1984;226(4678):1097-1099.

70. Leung LK, Wang TT. Paradoxical regulation of Bcl-2 family proteins by 17 beta-oestradiol in human breast cancer cells MCF-7. Br J Cancer. 1999;81(3):387-392.

71. Dawson SJ, Makretsov N, Blows FM, et al. BCL2 in breast cancer: a favourable prognostic marker across molecular subtypes and independent of adjuvant therapy received. Br J Cancer. 2010;103(5):668-675.

72. Abdel-Fatah TM, Perry C, Dickinson P, et al. Bcl2 is an independent prognostic marker of triple negative breast cancer (TNBC) and predicts response to anthracycline combination (ATC) chemotherapy (CT) in adjuvant and neoadjuvant settings. Ann Oncol. 2013;24(11):2801-2807.

73. Tawfik K, Kimler BF, Davis MK, Fan F, Tawfik O. Prognostic significance of Bcl-2 in invasive mammary carcinomas: a comparative clinicopathologic study between "triple-negative" and non-"triple-negative" tumors. Hum Pathol. 2012;43(1):23-30.

74. Nielsen KV, Ejlertsen B, Møller S, et al. The value of TOP $2 A$ gene copy number variation as a biomarker in breast cancer: Update of DBCG trial 89D. Acta Oncol. 2008;47(4):725-734.

75. Arriola E, Rodriguez-Pinilla SM, Lambros MB, et al. Topoisomerase II alpha amplification may predict benefit from adjuvant anthracyclines in HER2 positive early breast cancer. Breast Cancer Res Treat. 2007;106(2):181-189.

76. Mrklić I, Pogorelić Z, Ćapkun V, Tomić S. Expression of topoisomerase II- $\alpha$ in triple negative breast cancer. Appl Immunohistochem Mol Morphol. 2014;22(3):182-187.

77. Calhoun BC, Lanigan C, Rubin B, Mrazeck KC, Rosa C, Barnes M. TOP2A-based prognostication in triple negative breast cancer and correlation with basal phenotype. J Clin Oncol. 2015;33(Suppl 15):1098.

78. Rao AM, Hatcher JF, Dempsey RJ. Lipid alterations in transient forebrain ischemia: possible new mechanisms of CDP-choline neuroprotection. J Neurochem. 2000;75(6):2528-2535.

79. Dubois RN, Abramson SB, Crofford L, et al. Cyclooxygenase in biology and disease. FASEB J. 1998;12(12):1063-1073.

80. Costa C, Soares R, Reis-Filho JS, Leitão D, Amendoeira I, Schmitt FC. Cyclo-oxygenase 2 expression is associated with angiogenesis and lymph node metastasis in human breast cancer. J Clin Pathol. 2002;55(6):429-434.

81. Subbaramaiah K, Norton L, Gerald W, Dannenberg AJ. Cyclooxygenase-2 is overexpressed in HER-2/neu-positive breast cancer: evidence for involvement of AP-1 and PEA3.J Biol Chem. 2002;277(21):18649-18657.

82. Witton CJ, Hawe SJ, Cooke TG, Bartlett JM. Cyclooxygenase 2 (COX2) expression is associated with poor outcome in ER-negative, but not ER-positive, breast cancer. Histopathology. 2004;45(1):47-54.

83. Klapper LN, Glathe S, Vaisman N, et al. The ErbB-2/HER2 oncoprotein of human carcinomas may function solely as a shared coreceptor for multiple stroma-derived growth factors. Proc Natl Acad Sci U S A. 1999;96(9):4995-5000.

84. Karamouzis MV, Dalagiorgou G, Georgopoulou U, Nonni A, Kontos M, Papavassiliou AG. HER-3 targeting alters the dimerization pattern of ErbB protein family members in breast carcinomas. Oncotarget. 2016;7(5):5576-5597.

85. Witton CJ, Reeves JR, Going JJ, Cooke TG, Bartlett JM. Expression of the HER1-4 family of receptor tyrosine kinases in breast cancer. $J$ Pathol. 2003;200(3):290-297.

86. Torrisi R, Rotmensz N, Bagnardi V, et al. HER2 status in early breast cancer: relevance of cell staining patterns, gene amplification and polysomy 17. Eur J Cancer. 2007;43(16):2339-2344.

87. Chia S, Norris B, Speers C, et al. Human epidermal growth factor receptor 2 overexpression as a prognostic factor in a large tissue microarray series of node-negative breast cancers. J Clin Oncol. 2008;26(35):5697-5704. 
88. Schmidt G, Meyberg-Solomayer G, Gerlinger C, et al. Identification of prognostic different subgroups in triple negative breast cancer by Her2-neu protein expression. Arch Gynecol Obstet. 2014;290(6): 1221-1229.

89. Ilie SM, Desauw C, Hebbar M. HER2 based expression subpopulations in TNBC: pathological aspects and clinical significance. Ann Oncol. 2016;27suppl(6):vi15-vi42.

90. Thike AA, Iqbal J, Cheok PY, et al. Triple negative breast cancer: outcome correlation with immunohistochemical detection of basal markers. Am J Surg Pathol. 2010;34(7):956-964.
91. Rhee J, Han SW, Oh DY, et al. The clinicopathologic characteristics and prognostic significance of triple-negativity in node-negative breast cancer. BMC Cancer. 2008;8:307.

92. Kashiwagi S, Yashiro M, Takashima T, et al. Advantages of adjuvant chemotherapy for patients with triple-negative breast cancer at Stage II: usefulness of prognostic markers E-cadherin and Ki67. Breast Cancer Res. 2011;13(6):R122.

93. Miyashita M, Ishida T, Ishida K, et al. Histopathological subclassification of triple negative breast cancer using prognostic scoring system: five variables as candidates. Virchows Arch. 2011;458(1):65-72. 


\section{Supplementary materials}

Antibodies used for estrogen receptor (ER) and progesterone receptor (PR)

The ER and PR analyses were based on an immunohistochemistry (IHC) assay with nuclear staining that was performed with 1/200 dilutions of mouse antibodies anti-ER and clone SP1 (NeoMarkers, Fremont, CA, USA). An autostaining system was used (Ventana Medical Systems, Inc., Tucson, AZ, USA) in cases of the first variant, like the Allred score or mouse monoclonal antibody (mAb) clone EP1 at a dilution of 1/80 (Dako Denmark A/S, Glostrup, Denmark), or mouse antibodies anti-PR and clone SP2 at a dilution of 1/250 (NeoMarkers), or clone PgR636 at a dilution of 1/125 (Dako Denmark A/S).

\section{Antibodies used for human epidermal growth factor receptor 2 (HER2)}

HER2 membrane staining was assessed using a ready-to-use polyclonal rabbit antibody, anti-c-erbB-2 oncoprotein (Dako Denmark A/S) or rabbit mAb clone SP3 at a 1/500 dilution (NeoMarkers). ${ }^{1}$

HER2 positivity was defined according to the American Society of Clinical Oncology/College of American Pathologists (CAP) guidelines: 0 for the lack of staining or membrane positivity in $<10 \%$ of tumoral cells, 1 for incomplete and weak membrane staining in $>10 \%$ of tumoral cells, 2 for complete membrane staining of weak or moderate intensity in $>10 \%$ of tumoral cells, and 3 for complete, strong membrane staining in at least $10 \%$ of tumoral cells. Tumors exhibiting equivocal HER2 expression, denoted as 2+ membranous staining of tumor cells, were confirmed by fluorescence in situ hybridization (FISH) at an outside laboratory. Signal ratios (HER2/CEP17) of $\geq 2.2$ were classified as amplified according to CAP guidelines at the time. In the absence of positive FISH data, tumors that scored $2+$ by IHC were considered negative for HER2. ${ }^{2}$

\section{Antibodies used for EGFR, cytokeratin 5/6 (CK5/6), E-cadherin (E-cad), p53, B-cell lymphoma 2 (Bcl2), topoisomerase II alpha (TOP2A), and cyclooxygenase-2 (Cox-2)}

Immunostaining for CK5/6, EGFR, and E-cad was performed using the following mAbs: mouse $\mathrm{mAb}$ anti-CK5/6, clone D5/16B4 (Dako Denmark A/S), dilution 1/100; mouse mAb anti-EGFR, clone 2-18C9 (Dako Denmark A/S), readyto-use; and anti-E-cad, mouse mAb, clone NCH38 (Dako Denmark A/S), dilution 1/75.

The antibody used for $\mathrm{p} 53$ was mouse monoclonal, with clone DO-7 (Dako Denmark A/S) at a dilution of 1/400, with nuclear staining. The antibody used for $\mathrm{Bcl} 2$ was mouse $\mathrm{mAb}$, with clone 124 (Dako Denmark A/S) at a dilution of 1/100, with cytoplasmic staining. The antibody used for TOP2A was mouse mAb, with clone KiS1 (Dako Denmark A/S) at a dilution of $1 / 100$ with nuclear staining. Cox-2 was stained with a mAb (Cayman Chemical, Ann Arbor, MI, USA) at a dilution of $1 / 50$.

\section{References}

1. Ricardo SAV, Milanezi F, Carvalho ST, Leitão DR, Schmitt FC. HER2 evaluation using the novel rabbit monoclonal antibody SP3 and CISH in tissue microarrays of invasive breast carcinomas. J Clin Pathol. 2007;60(9):1001-1005.

2. Wolff AC, Hammond ME, Schwartz JN, et al; American Society of Clinical Oncology/College of American Pathologists. American Society of Clinical Oncology/College of American Pathologists guideline recommendations for human epidermal growth factor receptor 2 testing in breast cancer. Arch Pathol Lab Med. 2007;131(1):18-43.
Breast Cancer - Targets and Therapy

\section{Publish your work in this journal}

Breast Cancer - Targets and Therapy is an international, peerreviewed open access journal focusing on breast cancer research, identification of therapeutic targets and the optimal use of preventative and integrated treatment interventions to achieve improved outcomes, enhanced survival and quality of life for the cancer patient.

\section{Dovepress}

The manuscript management system is completely online and includes a very quick and fair peer-review system, which is all easy to use. Visit http://www.dovepress.com/testimonials.php to read real quotes from published authors. 